\title{
INFLUÊNCIA DAS DIMENSÕES DA BIOMASSA ESTOCADA DE Pinus taeda L. E Eucalyptus dunnii Maiden NA QUALIDADE DO COMBUSTÍVEL PARA GERAÇÃO DE ENERGIA ${ }^{1}$
}

\author{
Martha Andreia Brand², Graciela Inês Bolzon de Muñiz ${ }^{3}$, José Otávio Brito ${ }^{4}$ e Waldir Ferreira Quirino ${ }^{5}$
}

\begin{abstract}
RESUMO - Este trabalho teve por objetivo determinar a influência das dimensões de biomassa sobre as alterações em suas propriedades durante a estocagem, visando seu uso na geração de energia. O experimento foi realizado no Município de Lages, SC, entre outubro de 2003 e fevereiro de 2005. Foram utilizadas toras com casca de Pinus taeda L. e Eucalyptus dunnii Maiden e costaneiras de Pinus spp., estocadas em pilhas, por um período de seis meses. As amostras para análise foram coletadas no estado recém-colhido, com dois, quatro e seis meses de estocagem. Foram utilizados quatro lotes, colhidos e armazenados segundo as estações do ano, permanecendo sob estocagem entre os meses de outubro a maio, janeiro a agosto, maio a novembro e agosto a fevereiro. As propriedades avaliadas foram: teor de umidade na base úmida, poder calorífico superior e líquido e teor de cinzas. As dimensões tiveram maior influência no teor de umidade e poder calorífico líquido. As costaneiras de Pinus sofreram maior perda de umidade, maior ganho de poder calorífico superior e inferior e menor teor de cinzas durante a estocagem. A costaneira foi também o material mais heterogêneo, com relação às variações ocorridas no armazenamento. As toras de Pinus tiveram a menor perda de umidade e o menor ganho energético. De forma geral e considerando as propriedades mais importantes para a geração de energia, as dimensões da biomassa tiveram maior influência que a espécie sobre a qualidade da biomassa na estocagem.
\end{abstract}

Palavras-chave: Pinus taeda L.; Eucalyptus dunnii Maiden; Estocagem.

\section{INFLUENCE OF SIZE AND SHAPE OF FOREST BIOMASS, STORED IN PILES, ON QUALITY OF WOOD FUEL}

\begin{abstract}
The objective of the present study was to determine the influence of the size and shape of the biomass on the changes in its properties during storage, aiming its use on energy production. The experiment was conducted in Lages - Santa Catarina State, Brazil, from October 2003 to February 2005. Logs with bark of Pinus taeda L. and Eucalyptus dunnii Maiden, and Pinus spp edge, were stored in piles for six months. Samples for analysis were collected in freshly harvested state, with two, four and six months of storage. Four batches, collected and stored were used according to the seasons of the year, remaining in storage from October to May, from January to August, from May to November and from August to February. The properties evaluated were: moisture content in wet basis, gross and net calorific value and ash content. The shape and size had greater influence on the moisture content and on net calorific value. The pine edge suffered greater loss of moisture content, higher gain and lower gross calorific value and lower ash content during storage. This material was also the most heterogeneous, with respect to changes occurred during storage. The logs of Pinus had the lowest moisture loss and lower energy gain. In general, and considering the most important properties for generating energy, the size of the material had greater influence than the species on the behavior of biomass storage.
\end{abstract}

Keywoods: Pinus taeda L.; Eucalyptus dunnii Maiden; Particles size distribution..

\footnotetext{
${ }^{1}$ Recebido em 24.09.2010 aceito para publicação em 27.11.2013.

${ }^{2}$ Universidade do Estado de Santa Catarina, Centro Agroveterinário, Departamento de Engenharia Florestal. E-mail: <a2mab@cav.udesc.br>.

${ }^{3}$ Universidade Federal do Paraná, Departamento de Engenharia e Tecnologia Florestal. E-mail:<gbmunize@ufpr.br>.

${ }^{4}$ Escola Superior de Agricultura Luiz de Queiroz, Departamento de Ciências Florestais. E-mail:<jotbrito@esalq.usp.br>.

${ }^{5}$ Ministério do Meio Ambiente e da Amazonia Legal, Instituto Brasileiro do Meio Ambiente, Laboratório de Produtos Florestais, Brasília, Brasil. E-mail:<waldir.quirino@ibama.gov.br>.
} 


\section{INTRODUÇÃO}

O fato de as indústrias de base florestal gerar grandes quantidades de resíduos no processo produtivo não é novidade. Porém, o aumento progressivo da quantidade de madeira desdobrada tem revelado o problema da disponibilização de quantidades ainda maiores de resíduos, que muitas vezes não têm utilização na indústria onde foram gerados (BRAND et al., 2004).

Uma das alternativas de uso para esse material é, sem dúvida, a geração de energia. Porém, para tanto, a biomassa precisa receber o tratamento adequado para a melhoria da qualidade do material, de modo a gerar energia de forma eficiente. Uma das etapas do tratamento da biomassa que contribui de forma significativa para a melhoria da qualidade do combustível é a estocagem.

A estocagem, por sua vez, pode ser realizada na biomassa florestal oriunda de diferentes fontes: florestas nativas, florestas plantadas, ou resíduos da indústria de transformação mecânica ou química da madeira (BRAND, 2010).

Qualquer que seja a fonte, porém, o material disponível para a estocagem terá formas e tamanhos variados. Quando oriundos de resíduos industriais, estarão na forma de cavacos, serragem, costaneiras, refilos e destopos; quando oriundos de florestas nativas ou plantios florestais, estarão na forma de ponteiras de árvores, toras e galhos com e sem folhas (BRAND, 2010).

A forma mais comum de armazenamento, principalmente na indústria, é em cavacos. Nesse contexto, o tamanho das partículas tem grande influência sobre a velocidade e intensidade das alterações ocorridas nas propriedades físicas, químicas e energéticas da biomassa ao longo do tempo de estocagem. Essas variações são mais intensas e rápidas em partículas menores (cavacos), em comparação com a biomassa de maiores dimensões (toras e árvores inteiras).

Nos cavacos, em comparação com árvores inteiras ou toras, ocorrem maiores perdas de massa e, consequentemente, redução da massa específica básica; aumento mais rápido da temperatura, principalmente nas fases iniciais da estocagem; aumento da permeabilidade da madeira devido ao ataque de fungos e bactérias, o que resulta no aumento da higroscopicidade, podendo causar aumento no teor de umidade da biomassa ao longo do tempo de estocagem e perda mais rápida dos extrativos e, no caso de períodos mais longos de estocagem, variações mais intensas nas proporções de lignina, celulose e polioses. Consequentemente, as propriedades energéticas serão alteradas em maior proporção em partículas menores, em comparação com a biomassa estocada com maiores dimensões.

Essas diferenças relativas à influência das dimensões nas propriedades da biomassa sob estocagem foram observadas e relatadas por pesquisadores como Thörnqvist (1985), Jirjis (1995), Garstang et al. (2002) e Jirjis (2005), instigando e continuando a incentivar pesquisas para estocagem da biomassa com maiores dimensões.

De forma geral, a estocagem da biomassa na forma de toras ou árvores inteiras promove alterações mais lentas nas propriedades físicas, químicas e energéticas da biomassa, porém mais estáveis. Além disso, as alterações desejadas como manutenção ao ganho de poder calorífico são mais rápidas, enquanto a perda de massa e a degradação química e biológica da biomassa são reduzidas. No entanto, deve-se lembrar de que certos volumes de madeira para combustível precisam ser estocados na forma de partículas, servindo como estoque regulador (JIRJIS, 1995).

A dimensão da partícula de madeira afeta, portanto, os resultados da estocagem, pois estudos comparando a estocagem de biomassa com grandes dimensões e cavacos têm demonstrado que a perda de massa e de teor de umidade é menor na estocagem da biomassa de maior dimensão. Nesse sentido, Jirjis (1995), trabalhando na Suécia com estocagem de toras e resíduos florestais, constatou que o conteúdo de umidade da biomassa na forma de toras decresceu de aproximadamente $50 \%$ para $40 \%$, depois de um inverno e verão estocados. Esses resultados levaram o autor à conclusão de que a umidade da biomassa na forma de toras decresce rapidamente se o material é estocado em pequenas pilhas durante o verão, com maior risco de reumedecimento no caso de épocas de alta umidade.

Em contrapartida, a estocagem da biomassa florestal, em tamanho reduzido (cavacos) em pilhas, redistribui a umidade de forma que a região central fica mais seca e a região mais superficial da pilha fica mais úmida. Em geral, o limite entre as duas áreas é muito nítido (THÖRNQVIST, 1982 citado por THÖRNQVIST, 1985). Além disso, os microrganismos colonizam o material 
orgânico em maior ou menor grau, durante a estocagem. O armazenamento da biomassa florestal em várias formas, especialmente quando em tamanho reduzido, frequentemente cria condições favoráveis para esses organismos que são fortes produtores de esporos. Em condições favoráveis (combustíveis florestais em tamanho reduzido, armazenados em pilhas sem cobertura), a razão de reprodução pode ser maior e haverá riscos de reações alérgicas em quem manuseia o material (THÖRNQVIST; LUNDSTRÖN, 1980; THÖRNQVIST; LUNDSTRÖN, 1982 citados por THÖRNQVIST, 1985).

Jirjis (2005) avaliou a influência do tamanho das partículas e da altura das pilhas na qualidade energética de ramos particulados de Salix. Concluiu, em relação à umidade, que quanto menor o tamanho da partícula, maior a variação da umidade na altura da pilha e maior a perda de umidade durante a estocagem. Lehtikangas e Jirjis (1995 citados por JIRJIS, 1995) mencionaram que isso ocorre porque partículas menores absorvem mais umidade que as maiores, em períodos de umidade, e mais rápida também é a desorção em condições que favoreçam a secagem.

Com relação ao poder calorífico, Jirjis (2005) concluiu que a variação nessa propriedade foi pequena em períodos de estocagem de dois a três meses, independentemente do tamanho das partículas e da altura da pilha.

Thörnqvist (1986) encontrou variações energéticas devido ao aumento ou diminuição do poder calorífico superior entre $+2,5 \%$ e $-12 \%$, em um período de estocagem de oito meses, para madeira na forma de cavacos. Thörnqvist (1982 citado por THÖRNQVIST, 1985) obteve perdas energéticas de 6,8 a 21,4\% em pilhas de biomassa florestal estocada na forma de cavacos, por um período de seis a nove meses. Thörnqvist (1984) verificou perdas do conteúdo de energia em torno de $18 \%$ na biomassa recém-colhida e particulada, estocada por um período de seis meses. No entanto, quando a biomassa não foi transformada em cavacos, em estocagem por seis meses o ganho foi de $2 \%$ no conteúdo energético.

O tamanho das pilhas também tem influência sobre a variação energética. Pois Nylinder e Thörnqvist (1981 citados por THÖRNQVIST, 1985) observaram ganhos energéticos de $4 \%$ em pequenas pilhas (aproximadamente $120 \mathrm{~m}^{3}$ empilhados na forma de meda) de biomassa florestal estocada por nove meses. Enquanto Thörnqvist (1983 citado por THÖRNQVIST, 1985) verificou perda de 3\%, em biomassa estocada em grandes pilhas (aproximadamente $600 \mathrm{~m}^{3}$ empilhados na forma de meda), por um período de seis meses. O tamanho da pilha está relacionado à velocidade de secagem e alterações químicas pela perda ou modificação dos extrativos que protegem a madeira da biodegradação e da consequente perda de massa. Em pilhas pequenas, a velocidade de secagem é maior e as perdas e alterações de extrativos são menores, resultando em manutenção da massa, promovendo ganhos energéticos e ocorrendo o inverso em pilhas maiores.

Quando o período foi estendido para oito meses, em grandes pilhas, Thörnqvist (1986 citado por THÖRNQVIST, 1988) concluiu que as modificações energéticas no combustível variaram entre aumento em energia de $2,5 \%$ e perda de $12 \%$. As variações dependeram das diferentes espécies de árvores, diferentes umidades no momento da confecção das pilhas e também dos diferentes métodos de preparação destas. Portanto, pode-se concluir, com base nos trabalhos desenvolvidos por Thörnqvist (1984,1985, 1986, 1988), que sob as mesmas condições de análise (condições climáticas, forma de proteção das pilhas e outras variáveis que possam interferir nos resultados), para diferentes tamanhos de partícula, a estocagem na forma de cavacos em grandes pilhas promove perdas energéticas maiores, enquanto na biomassa com maiores dimensões em pilhas menores há ganhos energéticos durante a estocagem.

Para que a eficiência e rendimento da conversão da bimassa em energia sejam aumentados, deve-se, assim, ter o controle sobre o tipo de material que será colocado sob estocagem. Isso porque a espécie, a época de colheita, a época de estocagem, o tempo que a biomassa fica sob armazenamento e a origem do material têm influência sobre o comportamento da biomassa perante o armazenamento (BRAND; MUÑIZ, 2010, 2012; BRAND et al., 2010, 2011, 2012). Esses fatores afetam, em maior ou menor intensidade, a velocidade e homogeneidade na perda de umidade, alterações químicas e biodegradação da biomassa, que, por sua vez, levam à perda de massa seca, mudanças no conteúdo energético e riscos de incêndio. Tais fatores determinam ainda a forma de estocagem, que pode ser em pilhas, leiras, fardos ou outras formas; o volume estocado; o tempo de estocagem; e o manejo do material antes, durante e depois dessa operação.

Revista Árvore, Viçosa-MG, v.38, n.1, p.175-183, 2014 
Levando em consideração esses fatores, este trabalho objetivou a determinação da influência da forma e tamanho da biomassa sobre as alterações em suas propriedades, durante a estocagem, visando ao seu uso na geração de energia.

\section{MATERIAL E MÉTODOS}

O estudo foi realizado em Lages, Santa Catarina, entre outubro de 2003 e fevereiro de 2005. A cidade fica situada a $27^{\circ} 30^{\prime}$ de latitude Sul e a $50^{\circ}$ de longitude Oeste, com altitude entre 800 e $900 \mathrm{~m}$. Conforme a classificação climática de Köppen, essa região pertence ao tipo Cfb, caracterizado por verão fresco, e não apresenta déficit hídrico (LEITE et al., 1973). Os dados meteorológicos do período de estudo estão apresentados na Tabela 1.

Foram utilizadas toras com casca de Pinus taeda L. e Eucalyptus dunnii Maiden, com diâmetros variados ${ }^{6}$ e comprimento médio de 2,4 m; e costaneiras de Pinus spp. oriundas do desdobro de toras em serraria, com comprimento médio de $2 \mathrm{~m}$. Cada material foi estocado, separadamente, em pilhas (6 m de comprimento x 2,5 m de largura x 2,5 m de altura). Foram analisados quatro lotes de cada material, que permaneceram sob estocagem durante seis meses, com coletas no material recém-colhido, com dois, quatro e seis meses, com estocagem em diferentes épocas do ano. As épocas de estocagem foram de outubro a maio (Lote 1 ), janeiro a agosto (Lote 2 ), maio a novembro (Lote 3) e agosto a fevereiro (Lote 4) (Tabela 2).

$\mathrm{Na}$ Tabela 2, as zonas escuras indicam o período de avaliação dos lotes, e os $\mathrm{X}$ marcados indicam os momentos de coleta no experimento.
As amostras foram coletadas na base, meio e topo das pilhas. Sem haver remoção da casca, as toras e costaneiras foram transformadas em cavacos, utilizados na determinação das propriedades físicas e químicas. O teor de umidade na base úmida, poder calorífico superior e líquido e teor de cinzas foram analisados segundo as normas ABNT 2003 - NBR 14929; DIN 2000 - DIN 51900 e TAPPI 2002 - TAPPI 211, respectivamente.

A umidade ou conteúdo de umidade é a quantidade de água ou umidade presente na biomassa. Apesar de a umidade poder ser expressa na base seca e na base úmida ou verde, quando se utiliza a biomassa para a geração de energia o ideal é usar o teor de umidade na base úmida, pois ele expressa a quantidade de água no peso total da amostra que está sendo avaliada, na forma que será utilizada para a geração de energia (BRAND, 2010).

Além disso, o teor de umidade é utilizado para determinação do poder calorífico líquido ou na base úmida, e o uso do teor de umidade nessa base facilita a determinação da quantidade de energia útil disponível no combustível.

Segundo Brand (2010), o poder calorífico é a quantidade de calor total (energia térmica) que é liberado durante a combustão completa de uma unidade de massa ou de volume de combustível (kcal/kg ou kJ/kg; kcal/ $\mathrm{m}^{3}$ ou $\mathrm{kJ} / \mathrm{m}^{3}$ ). Assim, o valor obtido é teórico, pois a determinação é feita em recipiente hermeticamente fechado, onde é depositada a amostra, com $0 \%$ de umidade (totalmente livre de umidade). Após o encerramento do recipiente, é realizada uma descarga de oxigênio, com 99\% de pureza, seguida de uma descarga elétrica, que promove a ignição do combustível que está sendo testado.

Tabela 1 - Condições climáticas de Lages, SC (outubro de 2003 a fevereiro de 2005) ${ }^{1}$.

Table 1 - Climatic conditions in Lages, Santa Catarina State, Brazil (October 2003 to February 2005).

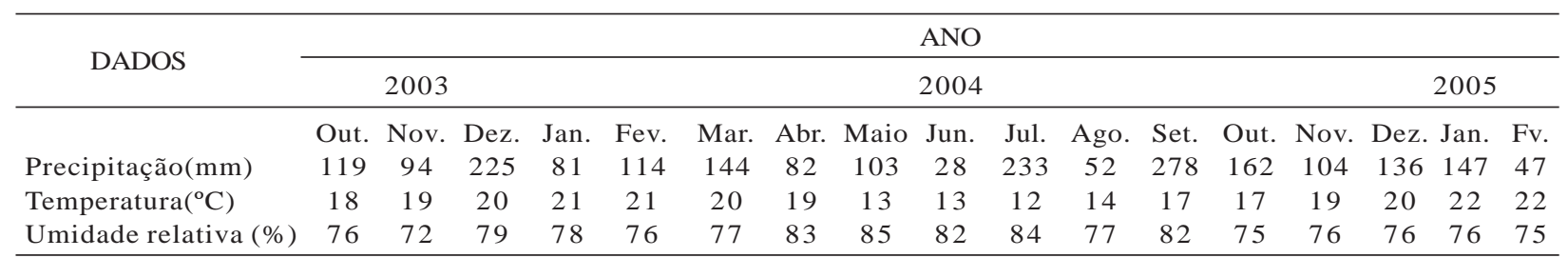

${ }^{1}$ A precipitação total do ano de 2004 foi de $1.517 \mathrm{~mm}$, e os valores médios de temperatura e umidade relativa foram $17{ }^{\circ} \mathrm{C}$ e $79 \%$, respectivamente. Os dados apresentados refletem as condições climáticas de anos típicos na região.

${ }^{6}$ Os diâmetros das toras variaram de $8 \mathrm{~cm}$ a mais de $30 \mathrm{~cm}$, pois o material de estudo foi constituído de madeira destinada à geração de energia (toras finas) e toras descartadas em processos industriais (toras grossas), sendo esta variável não controlada no estudo.

Revista Árvore, Viçosa-MG, v.38, n.1, p.175-183, 2014 
Nesse processo, a energia perdida na reação endotérmica da formação de água pelo hidrogênio contido no combustível não é perdida, devido ao fato de o recipiente ser fechado e, após a produção do vapor d'água, ele torna a condensar na parede do recipiente, permanecendo em um ciclo fechado. Como esse valor é teórico, para efeitos práticos é calculado o poder calorífico inferior, no qual é descontada a energia gasta para a liberação do hidrogênio de constituição. Portanto, o poder calorífico inferior (PCI), ao contrário do poder calorífico superior (PCS), é a quantidade de energia disponível, quando não se considera o calor latente de condensação da umidade presente nos produtos de combustão. Tanto o PCS quanto o PCI são calculados em base seca, ou seja, com $0 \%$ de umidade.

O poder calorífico inferior, no entanto, somente pode ser utilizado diretamente se o combustível não apresentar umidade livre, além da sua água de constituição. Quando o combustível tiver umidade livre, deve-se utilizar o poder calorífico inferior na base úmida ou poder calorífico líquido. Nesse caso, além da energia perdida para a liberação do hidrogênio de constituição, é descontada também a energia para evaporar a água livre do combustível.

A análise estatística foi feita através do teste F, para verificação da variação significativa e confirmação da variação através do teste de média de Tukey ( $P>0,05)$, considerando-se a variação entre as formas da biomassa nas duas espécies avaliadas (toras e costaneiras), em cada período de estocagem.

\section{RESULTADOS}

As variações nas propriedades da biomassa florestal das duas espécies avaliadas, na forma de costaneira e toras, podem ser visualidades na Tabela 3.

\subsection{UMIDADE}

As variações na umidade da biomassa florestal das duas espécies avaliadas, na forma de costaneira e toras, podem ser visualizadas na Figura 1.

\subsection{Poder calorífico}

As variações no poder calorífico superior e líquido para a biomassa florestal das duas espécies avaliadas, na forma de costaneira e toras, podem ser visualizadas na Figura 2.

\subsection{Teor de cinzas}

As variações no teor de cinzas para a biomassa florestal das duas espécies avaliadas, na forma de costaneira e toras, podem ser visualizadas na Tabela 3.

\section{DISCUSSÕES}

\subsection{Umidade}

A umidade variou ao longo do tempo de estocagem e foi influenciada pela espécie e pelas dimensões da biomassa.

No material recém-colhido, a biomassa apresentou umidade alta e estatisticamente igual, independentemente da espécie e dimensões do material. Com dois e quatro meses de estocagem, os materiais foram diferentes entre si, tanto em termos de espécie quanto de dimensões.

Na forma de tora, o Eucalyptus teve maior perda de umidade em comparação com o Pinus. Porém, a costaneira de Pinus teve a maior perda de umidade que as toras da mesma espécie. Isso indica que a dimensão da biomassa estocada teve maior efeito sobre a perda de umidade do que a espécie que deu origem ao combustível, concordando com o que observaram Garstang et al. (2002) e Jirjis (2005).

Tabela 2 - Delineamento experimental utilizado no estudo de estocagem de biomassa.

Table 2 - Experimental design used in the study of biomass storage.

\begin{tabular}{|c|c|c|c|c|c|c|c|c|c|c|c|c|c|c|c|c|c|}
\hline \multirow{2}{*}{$\begin{array}{l}\text { Ano } \\
\text { Mês }\end{array}$} & \multicolumn{3}{|c|}{2003} & \multicolumn{11}{|c|}{2004} & \multicolumn{3}{|c|}{2005} \\
\hline & 10 & 11 & 12 & 01 & 02 & 03 & 04 & 05 & 06 & 07 & 08 & 09 & 10 & 11 & 12 & 01 & 02 \\
\hline Lote 1 & $\mathrm{X}$ & $\mathrm{X}$ & & & & $\mathrm{X}$ & & $X$ & & & & & & & & & \\
\hline Lote 2 & & & & $\mathrm{X}$ & & & $\mathrm{X}$ & & $\mathrm{X}$ & & $X$ & & & & & & \\
\hline Lote 3 & & & & & & & & $\mathrm{X}$ & $\mathrm{X}$ & & & $\mathrm{X}$ & & $\mathrm{X}$ & & & \\
\hline Lote 4 & & & & & & & & & & & $\mathrm{X}$ & & $\mathrm{X}$ & $\mathrm{X}$ & & & $\mathrm{X}$ \\
\hline
\end{tabular}


Tabela 3 - Variação das propriedades da biomassa florestal em função da espécie, do tamanho e da forma da biomassa florestal, ao longo de seis meses de estocagem.

Table 3 -Variation of the properties of forest biomass, depending on the species, size and shape of forest biomass over six months of storage.

\begin{tabular}{|c|c|c|c|c|}
\hline Tipo de biomassa eTempo de estocagem & TU (\%) & PCS (kcal/kg) & PCL (kcal/kg) & TC $(\%)$ \\
\hline \multicolumn{5}{|l|}{ Toras de Pinus com casca } \\
\hline Recém-coletado & 59a & 4788a & 1479a & $0,45 a b$ \\
\hline Dois meses & $58 \mathrm{a}$ & $4806 a$ & $1545 c$ & $0,41 \mathrm{~b}$ \\
\hline Quatro meses & $46 a$ & 4839a & $2198 b$ & 0,39 a \\
\hline Seis meses & $51 \mathrm{a}$ & $4792 a$ & $1875 b$ & $0,43 \mathrm{~b}$ \\
\hline \multicolumn{5}{|l|}{ Toras de Eucalyptus com casca } \\
\hline Recém-coletado & $54 a$ & $4542 b$ & $1646 a$ & $0,78 \mathrm{a}$ \\
\hline Dois meses & $43 \mathrm{~b}$ & 4615b & 2204b & $1,02 \mathrm{a}$ \\
\hline Quatro meses & $34 b$ & $4616 \mathrm{c}$ & $2624 b$ & $0,61 \mathrm{a}$ \\
\hline Seis meses & $32 b$ & $4606 \mathrm{~b}$ & $2746 a$ & $0,97 a$ \\
\hline \multicolumn{5}{|l|}{ Costaneiras de Pinus } \\
\hline Recém-coletado & $54 a$ & 4743a & $1741 \mathrm{a}$ & $0,34 b$ \\
\hline Dois meses & $28 \mathrm{c}$ & $4779 a$ & $3056 a$ & $0,31 b$ \\
\hline Quatro meses & $15 c$ & $4715 \mathrm{~b}$ & $3674 a$ & $0,31 \mathrm{a}$ \\
\hline Seis meses & $28 \mathrm{~b}$ & $4845 a$ & 3093a & $0,35 b$ \\
\hline
\end{tabular}

TU = Teor de umidade na base úmida; PCS = Poder calorífico superior; PCL = Poder calorífico líquido; e TC = Teor de cinzas. NOTAS: Médias, NA LINHA (variação devida à forma e ao tamanho da biomassa para o mesmo tempo de estocagem), seguidas da mesma letra não diferem significativamente entre si (Tukey $\mathrm{P}>0,05$ ).

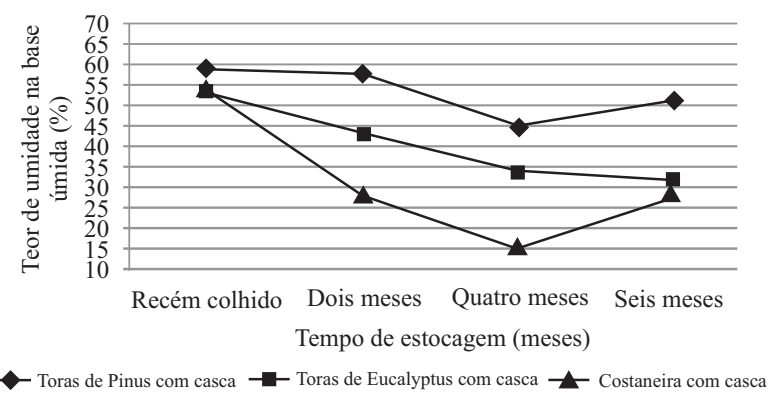

Figura 1 - Variação do teor de umidade na base úmida, em função da espécie e da forma e tamanho da biomassa florestal, ao longo de seis meses de estocagem.

Figure 1 - Variation of moisture content on wet basis, depending on the species, size and shape of forest biomass over six months of storage.

O conhecimento desse comportamento das espécies diante da estocagem permite ao produtor e usuário da biomassa para geração de energia tratar cada espécie de forma individualizada durante os processos de estocagem, o que permite a programação de colheita e uso, sabendo-se quanto tempo cada espécie precisa para atingir a umidade desejada. Além disso, dentro da espécie a alteração das dimensões permite ao produtor e usuário da biomassa acelerar a velocidade de perda de água durante o armazenamento.

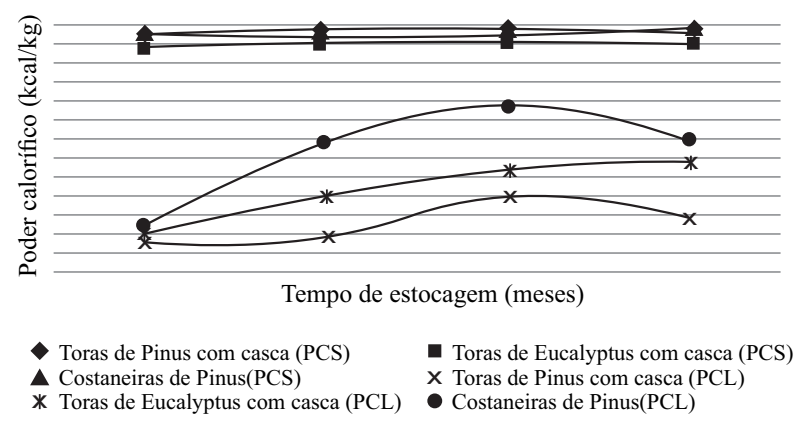

Figura 2 - Variação do poder calorífico superior e líquido, em função da espécie e da forma e tamanho da biomassa florestal, ao longo de seis meses de estocagem.

Figure 2 - Change in Gross and net calorific value, depending on the species, size and shape of forest biomass over six months of storage.

Após seis meses de estocagem, tanto as toras quanto as costaneiras de Pinus tiveram aumento na umidade, sendo esse aumento em maior proporção nas costaneiras do que nas toras. Já as toras de Eucalyptus mantiveram a umidade estável, sendo estatisticamente igual ao teor de umidade das costaneiras de Pinus. Esse aumento do teor de umidade é indicativo do início do processo de biodegradação, que segundo Thörnqvist (1985) contribui para o aumento do teor de umidade, perda de massa e consequente prejuízo para a eficiência

Revista Árvore, Viçosa-MG, v.38, n.1, p.175-183, 2014 
e rendimento energéticos da biomassa na geração de energia. Resultados da análise de biodegradação, feita por Brand (2007) no mesmo material avaliado neste trabalho, também confirmaram a hipótese de início de biodegradação após quatro meses de estocagem.

De forma geral, as costaneiras apresentaram os melhores resultados durante o período de estocagem, o que confirma as observações feitas por Jirjis (1995), podendo ser destinadas à geração de energia, já com dois meses de estocagem e perda contínua de umidade até quatro meses. O pior resultado, em contrapartida, foi das toras de Pinus, que, além de perderem menos água ao longo do tempo de estocagem, voltaram a absorvê-la depois de quatro meses de armazenamento.

\subsection{Poder calorífico}

Os valores de poder calorífico superior observado são compatíveis com os obtidos para biomassa florestal, variando de 4.600 a $4.900 \mathrm{kcal} / \mathrm{kg}$, como também observaram Vale e Felfili (2005). O maior valor médio de poder calorífico superior foi observado no Pinus com casca e o menor, no Eucalyptus com casca.

Na biomassa recém-colhida e até dois meses de estocagem houve alteração no poder calorífico entre as duas espécies avaliadas. No Pinus, a biomassa não apresentou diferenças no poder calorífico das toras em comparação com as costaneiras, nas condições anteriormente mencionadas. Ao final do tempo de estocagem, novamente existe diferença entre as espécies e não nas dimensões, dentro da mesma espécie (Pinus).

Para os três materiais analisados, houve ganho no poder calorífico, em relação aos valores iniciais, após seis meses de estocagem, da ordem de 2,15\%, $1,41 \%$ e $0,08 \%$ para a costaneira e toras de Eucalyptus e Pinus, respectivamente, concordando com o observado por Thörnqvist (1984), Jirjis (2005) e Almeida et al. (2010), com a ressalva de que este último obteve ganhos de $2 \%$ após seis meses de estocagem em biomassa com maiores dimensões.

Essas alterações provavelmente são devidas às alterações na composição química da madeira, observadas por Brand e Muñiz (2012), que afirmaram que o tempo de estocagem, de zero a seis meses, causou variações na composição química da biomassa florestal. Neste estudo, a biomassa de Pinus e Eucalyptus, durante os dois primeiros meses de estocagem, sofreram alterações em função de processos de oxidação e transformação dos extrativos, contribuindo para o aumento da solubilidade da madeira em água e álcool tolueno. Até seis meses ocorreram somente alterações nos extrativos, não havendo degradação da parede celular por processos de biodegradação, o que foi demonstrado pela redução da solubilidade em hidróxido de sódio ao longo do período de estocagem. Em razão disso, podem ocorrer pequenas alterações no poder calorífico superior pelas mudanças na composição química elementar, com aumento de moléculas de C e $\mathrm{H}$ e eventuais reduções de moléculas de $\mathrm{O}$.

As costaneiras de Pinus em todos os períodos de estocagem apresentaram maior quantidade de energia útil (maior poder calorífico líquido), em comparação com as toras, tanto de Pinus quanto de Eucalyptus. Porém, considerando a biomassa na forma de toras, o Eucalyptus teve maior ganho energético em comparação com o Pinus. Essas diferenças estão diretamente relacionadas à perda de umidade, cuja velocidade foi maior nas costaneiras, em comparação com as toras. Nas duas espécies na forma de toras, a perda de umidade foi mais rápida no Eucalyptus.

Esse comportamento comprova que, na mesma condição de estocagem, costaneiras terão melhor comportamento que toras, devido à menor quantidade de casca, que torna a madeira menos permeável a trocas de umidade com o meio e aumenta sua área superficial, que permite o aumento da velocidade de secagem e, consequentemente, do ganho de energia útil (poder calorífico líquido).

O tempo de estocagem ideal para o uso da biomassa foi de quatro meses, tanto para costaneiras quanto para toras, devido à umidade mais baixa (15\%, 34\% e $46 \%$ ) e ao maior poder calorífico líquido (3.674 kcal/ $\mathrm{kg} ; 2.624 \mathrm{kcal} / \mathrm{kg}$; e $2.198 \mathrm{kcal} / \mathrm{kg}$ ), respectivamente para costaneira de Pinus e toras de Eucalyptus e Pinus.

\subsection{Teor de cinzas}

O teor de cinzas varia em função do material que dá origem à biomassa (ALMEIDA et al., 2010; BRAND et al., 2011), não sendo influenciado pelas dimensões das peças durante o processo de estocagem.

A costaneira de Pinus apresentou o menor teor de cinzas durante todo o tempo de estocagem, devido à menor proporção de casca em relação à madeira, em comparação com as toras de Pinus e toras de Eucalyptus. Este último tipo de biomassa foi o material com maior

Revista Árvore, Viçosa-MG, v.38, n.1, p.175-183, 2014 
teor de cinzas, por se tratar de uma Angiosperma dicotiledônea, que naturalmente apresenta maior teor de cinzas que as Gimnospermas.

De forma geral, o teor de cinzas é baixo em ambas as espécies e diferentes dimensões das peças sob estocagem, sendo favorável ao uso para geração de energia. Neste estudo, o armazenamento não contribuiu para variações significativas no teor de cinzas ao longo do tempo, devido à baixa contaminação com terra, pedra e outros contaminantes durante a permanência da biomassa no pátio de estocagem. Almeida et al. (2010) também observaram esse comportamento quando estudaram Pinus patula sob estocagem. Isso porque a intensidade de manuseio da biomassa foi baixa e controlada durante a coleta das amostras para análise.

No entanto, deve-se lembrar de que a intensidade de manuseio da biomassa desde sua colheita até a estocagem e depois desta até o uso final para geração de energia pode aumentar significativamente o teor de cinzas. Brand (2010) mensurou teores de cinzas de até $15 \%$ ou mais em amostras de casca de Pinus coletada em pátios de tora de serrarias.

\section{CONCLUSÕES}

a)A espécie que dá origem à biomassa florestal teve maior influência sobre as variações no poder calorífico superior e no teor de cinzas.

b) As dimensões da biomassa estocada tiveram influência sobre as variações ocorridas na umidade e poder calorífico líquido, sendo essas as propriedades com maior influência sobre a qualidade da biomassa para geração de energia.

c) O tempo de estocagem ideal, independentemente da espécie ou das dimensões da biomassa estocada, foi de quatro meses, havendo perda na qualidade da biomassa após esse período.

d) O material que teve melhor resultado durante a estocagem foi a costaneira de Pinus, com maior perda de umidade, maior ganho em energia útil (poder calorífico líquido) e menor teor de cinzas.

e) A costaneira foi o material mais heterogêneo, em relação às variações ocorridas durante o tempo de estocagem.

f) As toras de Pinus com casca sofreram as menores alterações durante o período de estocagem, tendo ainda a menor perda de umidade e o menor ganho energético. g) De forma geral, as dimensões da biomassa tiveram maior influência sobre a sua qualidade na estocagem que a espécie, considerando-se o uso para geração de energia.

\section{REFERÊNCIAS}

\section{ASSOCIAÇÃO BRASILEIRA DE NORMAS} TÉCNICAS - ABNT. NBR 14929: Madeira Determinação do teor de umidade de cavacos Método por secagem em estufa. Rio de Janeiro: 2003.

ALMEIDA, N. F. et al. Avaliação das propriedades dos resíduos de Pinus patula em diferentes períodos de armazenamento visando a cogeração de energia. Floresta [online]. v.40, n.2, p.269274, 2010.

BRAND, M. A. Energia de biomassa florestal. Rio de Janeiro: Interciência, 2010. 114p.

BRAND, M. A. et al. Influência da época de estocagem na qualidade da biomassa florestal para a geração de energia. Floresta [online]. v.42, p.369-380, 2012.

BRAND, M. A. et al. Influence of storage time of the quality of biomass for energy production in humid subtropical regions. Cerne [online], v.16, p.531- 537, 2010.

BRAND, M. A. et al. Storage as a tool to improve wood fuel quality. Biomass \& Bioenergy [online]. v.35, p.2581-2588, 2011.

BRAND, M. A.; MUÑIZ, G. I. B. Influência da época de colheita da biomassa florestal sobre sua qualidade para a geração de energia. Scientia Forestalis [online], v.38, p.619-628, 2010.

BRAND, M. A.; MUÑIZ, G. I. B. Influência da época de colheita e da estocagem na composição química da biomassa florestal. Floresta e Ambiente [online]. v.19, p.66-78, 2012.

BRAND, M. A. et al. Avaliação do processo produtivo de uma indústria de manufatura de painéis por meio do balanço de material e do rendimento da matéria-prima. Revista Árvore [online], v.28, n.4, p.553-562, 2004. 
BRAND, M. A. Qualidade da biomassa florestal para o uso na geração de energia em função da estocagem. 2007. 168f. Tese (Doutorado Engenharia Florestal) - Universidade Federal do Paraná, Curitiba, 2007.

DEUTSCHES INSTITUT FÜR NORMUNG e. V. DIN 51900: Determining the gross calorific value of solid and liquid fuels using the bomb calorimeter, and calculation of net calorific value. Berlin: 2000.

EPAGRI. Estação meteorológica. Lages: Estação Experimental de Pesquisa Agropecuária de Lages, 2006.

GARSTANG, J. et al. Identification and characterisation of factors affecting losses in the large-scale, nonventilated bulkstorage of wood chips and development of best storage practices. FES B/W2/00716/RESP.DTI/Pub urn 02/1535, 2002. 116p. Relatório técnico.

JIRJIS, R. Effects of particle size and pile height on storage and fuel quality of comminuted Salix viminalis. Biomass and Bioenergy, v.28, n.1, p.193-201, 2005.

JIRJIS, R. Storage and drying of wood fuel. Biomass and Bioenergy. v.9, n.1-5, p.181190, 1995.

LEITE, N. B. et al. Efeito de geadas sobre diversas espécies/procedências de Eucalyptus spp introduzidas na região de Lages - Santa Catarina. IPEF, n.7, p.101-114, 1973.
TECHNICAL ASSOCIATION FOR THE WOLDWIDE PULP, PAPER AND CONVERTING INDUSTRY - TAPPI standard Test Methods. TAPPI 211: Ash in wood, pulp, paper and paperboard: combustion at $525^{\circ} \mathrm{C}$. Atlanta: 2002 .

THÖRNQVIST, T. Drying and storage of forest residues for energy production. Biomass, v.7, n.1, p.125-134, 1985.

THÖRNQVIST, T. Projekt storskalig säsongslagring av trädbraänsle - en sammanfattning av etapp 1. Large-scale seasonal storage of tree fuel project - summary of phase 1. Sweden: The Swedish University of Agricultural Sciences. Department of Forest Products, 1986. 50p. Report n ${ }^{\circ} 188$.

THÖRNQVIST, T. Storing of forest residues and comminuted fuels from forest residues. In: CONFERENCE HELD BY THE INTERNATIONAL ENERGY AGENCY - IEA. - Forestry Energy Programme Group C - Storing, drying and internal handling of wood fuels, 1984, Denmark.

Proceedings.... Denmark: Danish Institute of Forest Technology, 1984. p.16-18.

THÖRNQVIST, T. Wood fuel storage in large piles - Mechanisms and risks of self-ignition. In: IEA/ BE CONFERENCE TASK III/Activity 6 and 7., 1988, Sweden. Proceedings... Sweden: Swedish University of Agricultural Sciences, Department of Operational Efficiency, 1988. p.193198.

VALE, A. T.; FELFILI, J. M. Dry biomass distribution in a cerrado sensu stricto site in Brazil central. Revista Árvore [online], v.29, n.5, p.661-669, 2005. 
